\title{
Endovascular approach to complex aortic arch pathologies: state of the art
}

\author{
Bartosz Rylski \\ Heart Centre Freiburg University, Freiburg, Germany \\ Kardiochirurgia i Torakochirurgia Polska 2016; 13 (1): 1-2
}

Aortic geometry changes during life [1]. After relatively dynamic aortic length and diameter growth in the first two decades of life, it continuous to grow, attaining diameters 20 to $30 \%$ larger in the $7^{\text {th }}$ than in the $2^{\text {nd }}$ decade. Arterial hypertension, atherosclerosis, and still poorly-defined genetic risk factors add to natural aortic anatomy changes leading to rapid aortic segmental growth and ultimately aneurysms. Aortic arch aneurysms together with arch dissections and penetrating atherosclerotic ulcers are the most common arch pathologies requiring further therapy.

New technologies give us an excellent opportunity to broaden the surgical armamentarium. Thoracic endovascular aortic repair (TEVAR) has dramatically changed aortic surgery within the last 15 years. It is not only a far less invasive approach than open surgery, but it also provides excellent results for complex pathologies in certain patients and may be applied even in those ineligible for open surgery $[2,3]$. Thoracic endovascular aortic repair became the treatment of choice for traumatic aortic injury and acute complicated type B dissection. Aortic arch pathologies due to the arch's key role in maintaining cerebral perfusion usually require complex treatment. Several hybrid surgical techniques have been developed in the last decade, which combine an endovascular and open approach to obtain better results. The hybrid approach includes hybrid surgical procedures (TEVAR combined with surgical rerouting of supraaortic vessels) and the hybrid devices originating from traditional prostheses employed during open and endovascular procedures. The hybrid approach to the aortic arch is associated with less trauma, usually no need for the heart-lung-machine, no need for hypothermia or artificial cerebral perfusion, and no risk or recurrent nerve paresis. The complications related to hybrid procedures include retrograde aortic dissection type $A$, endoleaks, and stentgraft migration.

According to the Penn classification, there are three types of hybrid approach to aortic arch pathologies [4]. Type I includes supraaortic vessels debranching using a 4 limb branched graft anastomosed to the very proximal ascending aorta (just above the sinotubular junction) and on the other side to all supraaortic vessels. The fourth branch is used to insert the stent graft in antegrade direction into the aortic arch. Type I is being performed only sporadically since it carries a relatively large risk of retrograde aortic dissection type A. Type I hybrid approach is contraindicated in case the ascending aorta diameter exceeds $3.8 \mathrm{~cm}$. More popular is type II hybrid approach consisting of creating a zone 0 landing zone by replacing the ascending aorta in an open fashion and debranching the supraaortic vessels similar to type I, followed by the TEVAR procedure [5]. Its main advantage is that it is not associated with the risk of retrograde dissection. However, it necessitates sternotomy and the heart-lung-machine. Penn type III hybrid approach is

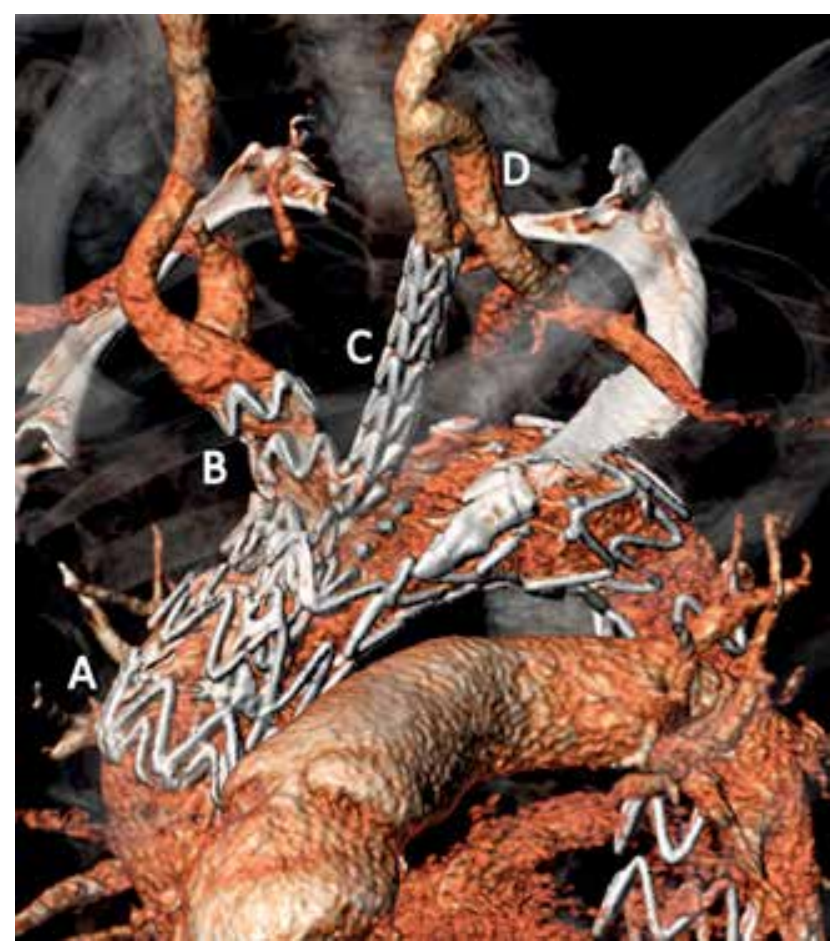

Fig. 1. Double inner branched stent graft in the aortic arch of the patient with penetrating atherosclerotic ulcer. $\mathbf{A}$ - aortic stent graft, B - brachiocephalic trunk, C - left carotid artery, D - carotidsubclavian bypass

Address for correspondence: Bartosz Rylski, MD, Heart Centre Freiburg University, Department of Cardiovascular Surgery, 55 Hugstetter St., 79106 Freiburg, Germany, phone: +49 761270 28180, fax: +49 761270 28670, e-mail: bartosz-rylski@universitaets-herzzentrum.de 
a frozen-elephant-trunk procedure that includes total aortic arch replacement and stentgraft implantation in the proximal descending thoracic aorta using a hybrid prosthesis.

Total endovascular arch replacement is now feasible, and two similar devices are already available. Both include one main stent graft specifically for implantation starting in the ascending and ending in the proximal thoracic descending aorta (Fig. 1). Both have 2 internal tunnels (inner branches) that are extended with stent grafts into the brachiocephalic trunk and the carotid artery. This operation requires prior carotid-subclavian bypass on the left side [6]. The ascending aorta diameter should not exceed $3.8 \mathrm{~cm}$.

The open-surgical approach to the aortic arch is the gold standard. Further development of less invasive endovascular treatment options is mandatory, since they may be beneficial for older patients with significant comorbidities who may not tolerate prolonged cross-clamp and circulatory arrest times. Transcatheter aortic valve implantation technology has not reduced the number of conventional aortic valve replacement procedures. Similarly, although endovascular aortic arch replacement is not likely to replace open surgery, it will expand our armamentarium and enable us to recruit new patients undergoing medical treatment only due to their excessive risk of conventional arch replacement.

\section{Disclosure}

Author reports no conflict of interest.

\section{References}

1. Rylski B, Desjardins B, Moser W, Bavaria JE, Milewski RK. Gender-related changes in aortic geometry throughout life. Eur J Cardiothorac Surg 2014; 45: 805-811.

2. Rylski B, Blanke P, Siepe M, Kari FA, Euringer W, Südkamp M, Beyersdorf F. Results of high-risk endovascular procedures in patients with non-dissected thoracic aortic pathology: intermediate outcomes. Eur J Cardiothorac Surg 2013; 44: 156-162.

3. Rylski B, Czerny M, Südkamp M, Siepe M, Beyersdorf F. The TEVAR App: a contemporary guide to thoracic endovascular aortic repair. Interact Cardiovasc Thorac Surg 2016; 22: 228-230.

4. Bavaria J, Vallabhajosyula P, Moeller P, Szeto W, Desai N, Pochettino A. Hybrid approaches in the treatment of aortic arch aneurysms: postoperative and midterm outcomes. J Thorac Cardiovasc Surg 2013; 145: S85-90.

5. Rylski B, Siepe M, Blanke P, Kari FA, Schoellhorn J, Beyersdorf F. Modified perfusion strategy and aortic arch debranching in complicated acute aortic dissection type A: a bridge to definitive endovascular therapy. Ann Thorac Cardiovasc Surg 2014; 20: 1038-1041.

6. Spear R, Haulon S, Ohki T, Tsilimparis N, Kanaoka Y, Milne CP, Debus S, Takizawa R, Kölbel T. Subsequent Results for Arch Aneurysm Repair with Inner Branched Endografts. Eur J Vasc Endovasc Surg 2016; 51: 380-385. 